\title{
História do ensino de História: desafios para uma nova escrita de síntese
}

\author{
History of History Teaching: \\ Challenges for a New Synthesis Writing
}

Alexandre Guilherme da Cruz Alves Junior* Margarida Maria Dias de Oliveira ${ }^{* *}$ Fábio Alves Alves dos Santos*** Itamar Freitas de Oliveiras ${ }^{\star * \star *}$

\section{RESUMO}

Este ensaio discute as formas como a experiência brasileira do ensino de História tem sido narrada e apropriada nas últimas décadas. Refletimos sobre algumas tomadas de decisão em termos teórico-metodológicos como a espacialização, a periodização e as motivações ideológicas que constituem os objetos de pesquisa. Assim sugerimos novas abordagens à uma futura escrita de síntese da História do Ensino de História. Palavras-chave: história do ensino de História; historiografia; escrita de síntese.

\section{ABSTRACT}

This essay discusses the ways in which the Brazilian experience of teaching history has been narrated and appropriated in recent decades. We reflect on some decisions in theoretical and methodological terms such as spatialization, periodization and the ideological motivations that constitute the objects of research. Additionally, we suggest new approaches to a future synthesis writing of the history of history teaching. Abstract: history of History teaching; historiography; synthesis writing.

As bases epistemológicas da Ciência Histórica não orientam apenas a busca pela explicação/compreensão (RICOUER, 2007) do passado, mas, principalmente, a própria elaboração das questões a serem investigadas, a partir de de-

\footnotetext{
* Universidade Federal do Amapá (UNIFAP), Macapá, AP, Brasil. alexandrecruzunifap@gmail. com

** Universidade Federal do Rio Grande do Norte (UFRN), Natal, RN, Brasil. margaridahistoria@ yahoo.com.br

*** Universidade Federal do Sergipe (UFS), Maceió, SE, Brasil. fabbioallves@gmail.com **** Universidade Federal do Sergipe (UFS), Maceió, SE, Brasil. itamarfreitasufs@gmail.com
} 
mandas diversas do presente. Nesse sentido, toda aula de História em um curso de graduação deve ser atravessada, necessariamente, pela História da Historiografia e pela Teoria da História (NEVES, 1980).

A primeira possibilita apreender o modo pelos quais se tem forjado a escrita da História e a Ciência Histórica ao longo do tempo, ou seja, critica e forma uma memória histórica que se consolida como saber instituído. A segunda orienta e situa o conhecimento produzido em termos de problemáticas, fontes, recortes espaciais, temporais, personagens, conceitos e resultados obtidos. Por essa razão, consideramos contraproducente a abordagem da História do ensino de História como conhecimento pronto e encerrado, a exemplo do que ocorre na maioria das disciplinas formadoras dos cursos de graduação que têm o ensinar e o aprender História como objeto privilegiado.

Neste artigo, problematizamos o modo como a experiência brasileira do ensino de História, gestada a partir dos anos 80 do século passado, vem sendo narrada. Objetivamente, questionamos algumas tomadas de decisão em termos teórico-metodológicos como a espacialização, a periodização e as motivações ideológicas que constituem os objetos de pesquisa.

Na sequência, sugerimos novas abordagens à uma futura escrita de síntese da História do ensino de História, exemplificando com duas formas de abordar um tipo bastante conhecido de fonte: os dispositivos legais. Aqui, demonstramos, brevemente, o valor heurístico da legislação educacional, compilada por Primitivo Moacyr (1869-1942), como também o valor das convenções americanas sobre ensino de História (1933).

Com esses dois exemplos, esperamos demonstrar que a dominante macro-narrativa sobre a experiência brasileira referente ao ensino de História nos levou a um impasse: ou reconhecemos e pluralizamos a escrita de síntese ou negamos princípios sedimentados nas comunidades dos historiadores, como o perspectivismo e a necessária mudança provocada entre espaços de experiência e horizontes de expectativas.

\section{PROBLEMATIZANDO AS HISTÓRIAS DO ENSINO DE HISTÓRIA}

Podemos aceitar como consensuais, hoje, as teses de que a atividade de ensinar História abrange a mobilização de estratégias, conhecimentos, sentimentos e valores relacionados à ciência da História com a finalidade de auxiliar 
no desenvolvimento daquelas capacidades de compreensão das experiências individuais e coletivas no tempo. Essa definição de ensino de História traz implícita a ideia de que o conhecimento histórico é uma produção controlada, cuja legitimidade e racionalidade estão diretamente ligadas a processos de intersubjetividade (WINEBURG, 2001; RÜSEN, 2015). Dessa forma, deve o graduando em História compreender e problematizar a História do ensino de História (historiografia) porque esses saberes, fazeres e valores modificam-se ao longo do tempo, isto é, como qualquer experiência humana, a tarefa de ensinar-aprender História está imersa no tempo (possui historicidade).

A outra justificativa, eminentemente prática, está no fato de que o conhecimento das atividades pretéritas do ensinar História tem relevância fundamental para a compreensão e o planejamento do dia a dia do professor e do seu futuro profissional. Dizendo de outro modo, sem o conhecimento da História do ensino de História, podemos simplesmente repetir, ficar presos a regras ou desobedecê-las inconsequentemente. E essas três atitudes permissivas, isoladas ou em conjunto têm um nome, com o qual nenhum professor quer ser identificado: prática acrítica.

Com base nessas justificativas, a maioria dos professores formadores que se aventuram em abordar a História do ensino de História no Brasil lança mão de uma dominante macro-narrativa que vai se impondo como lugar comum e que se estrutura em teses do tipo: "tudo de novo no chão da escola e na pesquisa sobre o chão da escola aconteceu após os anos 1980" e "tudo começou, no Rio de Janeiro e em São Paulo, com o Colégio Pedro II e a Universidade de São Paulo".

Essa narrativa de síntese, capilarizada em centenas de disciplinas que tratam do ensino de História pelo Brasil a fora, onde estão em funcionamento mais de 600 cursos de licenciatura e/ou bacharelado, é revivida, principalmente, em trabalhos de pós-graduação que, em boa parte, acreditam que a contextualização de qualquer objeto histórico é mediada por um texto que se perde no famoso ídolo das origens, velho pecado apontado por Francis Bacon, para a pesquisa nas ciências naturais, e recuperado por vários historiadores, inclusive Lucien Febvre, para a pesquisa sobre a História do ensino de História. Por mais que alguns orientadores aconselhem seus alunos, cortem os respectivos textos, a prática de começar do Colégio Pedro II, do Instituto Histórico e Geográfico Brasileiro (IHGB) e da Universidade de São Paulo (USP) vai ganhando 
cada vez mais espaço no início de dissertações e teses das áreas de Educação e de História.

Por que os professores de disciplinas como Didática da História, Fundamentos Teórico-Metodológicos do Ensino de História, Prática do Ensino de História e até de Estágio Supervisionado em Ensino de História agem dessa forma?

A resposta em termos de pesquisa em escala nacional, acerca da resiliência dessas teses ainda não existe. Mas ela pode ser buscada nos próprios trabalhos de pós-graduação, nos artigos em periódicos examinados por pares, nas coletâneas sobre ensino de História, nos livros autorais sobre metodologia do ensino de História e, ainda, nos manuais de professor dos livros didáticos de História distribuídos pelo Programa Nacional do Livro Didático (PNLD). Ela pode ser encontrada, o que é ainda mais espantoso e grave, nos programas de História do Ensino de História, disciplina obrigatória do Mestrado Profissional em História (Profhistória) que, hoje, está presente em 32 cidades e 20 estados e em todas as regiões do país, prática que legitima, inclusive, a sua replicação nas dissertações sobre ensino de História produzidas no âmbito do programa.

A macro narrativa não somente pode ser flagrada como uma prática nacional, como também pode ser descrita em seus principais elementos constituintes e, evidentemente, problemáticos.

\section{A ESCRITA DE SÍNTESE SOBRE A HISTÓRIA} DO ENSINO DE HISTÓRIA NO BRASIL

Com o arsenal de fontes tipificadas acima, nos foi possível identificar alguns pontos problemáticos, como também encadear as principais teses divulgadas nos trabalhos de síntese sobre a História do ensino de História no Brasil. Dois pontos problemáticos dessa macro-narrativa são o encadeamento causal diacrônico (cronologia) e periodização, os quais descreveremos ao final deste tópico. Essas quase-estruturas foram criadas pelos que escreveram histórias do ensino de História na década de 1980, marcados pelo pavor à escrita e ao ensino de História de caráter "tradicional" e ou "factual" e por uma mítica vinculação aos Annales, desde a emergência dessa suposta "escola”.

Esses pesquisadores afirmam que, no Brasil, todo o ensino experimentado durante a ditadura militar de 1964 a 1985 foi marcado pelos Estudos Sociais, 
pela despolitização com a retirada de Filosofia, Sociologia e a introdução da Educação Moral e Cívica e Organização Social e Política Brasileira, além de Estudos dos Problemas Brasileiros no ensino superior.

A esta cronologia está adicionada um suposto tradicionalismo caracterizador do ensino de História anterior a época, e que partiria do último quinto do século $\mathrm{XX}$, de onde falavam os pesquisadores, a proveniência de várias inovações, sobretudo àquelas designadas como "novas metodologias": a inclusão das tecnologias audiovisuais, da música, da história em quadrinhos, das artes e do patrimônio e, em contrapartida, a negação do livro didático como mediador do ensino e da aprendizagem.

Esse expurgo, em tese, do livro didático é, talvez, a mais significativa das inovações. Os pesquisadores do ensino de História dos anos 80 não inauguraram o estigma dos livros didáticos. Na primeira metade do século XX, orientados por escolanovistas e, depois, por construtivistas piagetianos, por exemplo, os estudiosos do ensino de História já denunciavam os perigos de limitar a metodologia do ensino ao emprego do livro didático pelo professor e pelo aluno. Mas os anos 80 são férteis em discursos que proclamavam a necessidade de abolir o tradicional (pouco definido e problematizado), imputado como matéria habitual nos livros didáticos, tipificada pejorativamente como história factual.

Hoje, é comum encontrarmos em textos sobre a História do ensino de História as classificações do tipo "história tradicional", "história factual", "história pátria" de modo irrefletido, reproduzindo uma pretensa legitimidade ancorada na primeira geração da chamada Escola Annales. Entretanto, é importante pontuar, como o fazem François Dosse (1994) e Peter Burke (2010), que os fundadores da Revista francesa exageraram na suposta estreiteza intelectual de seus predecessores, não apenas para colocarem-se como expoentes de uma nova historiografia, como para ocupar posições destacadas nas instituições daquele país.

Não por acaso, Ernest Lavisse, considerado o importante nome do ensino de História na França, no final do século XIX e início do século XX, foi uma das figuras mais atacadas por Marc Bloch, embora estivesse longe de produzir uma "história tradicional" tal qual os fundadores dos Annales o acusavam. Essa menção aos franceses não se trata de uma digressão. Foi na esteira das mudanças provenientes da apropriação de vários historiadores franceses, associados à rubrica dos Annales, que boa parte dos pesquisadores do ensino ganhou o 
status de especialistas no ensino de História. Esses mesmos pesquisadores foram quase unânimes em afirmar que os Cursos de História começaram no Brasil com a USP, em 1934 - e que esse curso, pela presença de Fernand Braudel, já nascia inovador. Assim, toda a historiografia brasileira seria tributária deste marco e circunscrita aos imaginados parâmetros epistemológicos dos Annales e, já nos anos 80 e 90 do mesmo século, da terceira geração ou Nova História.

Essas duas experiências - da instituição, no Brasil, de cursos superiores de História e da incorporação de elementos teórico-metodológicos das três gerações dos Annales -, apesar de temporalmente paralelas (simultâneas), não guardam relação de causa-consequência. Os textos de Maria de Lourdes Janotti (1997), Elza Nadai (2011) e de Thais Nívea Fonseca (2004), contudo, transmitem a ideia de que, não somente a formação inicial brasileira em História é teórico-metodologicamente francófilo annalista, como também sugerem que o ensino de História nos anos 80 seria renovado com os influxos da terceira geração.

Esse modo de pensar resultou em uma estrutura que vimos designanda por macro-narrativa, ou seja, a escrita de síntese sobre a História do ensino de História no Brasil. Essa narrativa é tanto mais perversa quanto mais necessárias são as escritas de síntese. O gênero é o mais popular, entre profissionais e entre não profissionais. Quando queremos jogar com as escalas, ou seja, interpretar o significado de um fato na cidade de Natal, no Estado do Rio Grande do Norte, na década de 30 do século XX à luz das linhas de força da educação nacional em uma duração secular, sempre recorremos à escrita de síntese. É uma prática antiga. A síntese é base para a comparação e a valorização de determinada experiência, da sua exemplaridade, do seu caráter desviante ou regular. Mas quando a empregamos, em virtude das demandas da nossa pesquisa e do peso (importante) que atribuímos à autoridade acadêmica, quase sempre desprezamos as insuficiências - as lacunas, as contradições e os determinismos irrefletidos.

A escrita de síntese sobre a História do ensino de História no Brasil, do modo como foi construída, transformou-se nos nossos "quadros de ferro", a exemplo da narrativa sobre a História do Brasil que tanto criticamos, estatista e oficial, que foi instituída pelo Visconde de Porto Seguro - "os quadros de ferro de Varnhagem". Criada por Janotti e Nadai e continuada por Fonseca, 
elas assumem as seguintes teses como guias da interpretação da experiência nacional (Quadro 1).

Essas teses que estruturam a síntese sobre a História do ensino de História no Brasil não resistem ao escrutínio dos fatos, efetuado pela pesquisa na área. Os textos de Manoel Salgado Guimarães, empregados para legitimar a primeira delas, não confirmam tal classificação. Além disso, a tese carrega o mal de raiz que é, como já adiantamos, não problematizar a palavra "tradicional" empregada como categoria analítica.

A segunda tese já foi testada como hipótese e já há indícios de que foi o Colégio Pedro II que ofereceu prestígio ao IHGB também como agência profissional em relação a escrita da História e não o contrário. Grande parte dos renomados historiadores do grêmio produziam livros didáticos de História para aquela instituição escolar.

As reformas Francisco Campos e Capanema, é verdade, são marcos institucionais instauradores de mudanças no contexto nacional. Contudo, as pesquisas não estabelecem relações de causa-feito, por exemplo, entre esses fenômenos e a experiência do ensino de História.

Quadro 1. Teses estruturantes da História do ensino de História no Brasil

1. O IHGB institui o ensino de História tradicional.

2. Entre a Primeira República e a década de 30 do século passado, mantém-se o ensino de História dito "tradicional" e homogêneo, marcado pelas orientações do Colégio Pedro II que, por sua vez, estaria orientado pelo IHGB, já que seus professores eram membros do grêmio.

3. As reformas Francisco Campos e Capanema, bem como os movimentos pela democratização da escola, sob a orientação, inclusive, de Anísio Teixeira, promovem a dinâmica educação nacional.

4. A década de 60 do século XX é caracterizada por movimentos, agitações e militância que parecem não incidir no ensino de História.

Conclusão: a década de 80 é o início de tudo que é novo em matéria de ensino de História no Brasil.

Sobre as agitações da década de 60 do século XX, por fim, não está provado que a despolitização da disciplina escolar História e a diminuição da sua carga horária tenham resultado em retrocesso no ensino de História.

Não obstante as fragilidades dessas teses, os nexos causais, a espacialização e a periodização se mantêm, como afirmamos, desde os trabalhos de pós-gra- 
duação aos manuais de professor do livro didático de História. A História de síntese do ensino de História é contada a partir de São Paulo, sob o cenário da capital do Brasil, o Rio de Janeiro. Os períodos são determinados pelas mudanças no Estado nacional e, consequentemente, os nexos causais são estabelecidos com base na ideia de que o ensino de História é, dominantemente, caixa de ressonância dos debates dicotômicos do tipo centralização versus descentralização, monarquia versus república, ditadura versus democracia.

\section{A COMPARAÇÃO SUBNACIONAL}

A estrutura dessa macro-narrativa pode ser alterada? Pode sim. Pode e é importante que mude, sob pena de contraditarmos (como afirmamos no tópico 1) a consensual perspectividade e de sermos infiéis às diferenças provocadas pelos jogos que indivíduos e comunidades fazem entre o que experimentam dos seus passados e esperam dos seus futuros.

As questões formuladas a partir de diferentes escalas e tempos tenderiam a nos oferecer possibilidades de respostas para além de uma história diacrônica do ensino de História. O postulado do jogo de escalas preconizado por Jacques Revel (1998) não apenas poderia revelar novas "histórias" do ensino de História, como também jogaria luz sobre as clivagens, conflitos e contradições nas políticas formuladas em escala nacional, com seus diferentes níveis de recepção em contextos diversos.

Duas possibilidades queremos ressaltar. A primeira, bem conhecida de todos nós, é a viabilidade do exame comparado de experiências subnacionais. A segunda nos leva aos estudos transnacionais.

A efetivação de pesquisas comparadas em termos subnacionais pode ser facilitada por causa de trabalhos realizados há décadas por historiadores da Educação. Podemos revisitar reformas e dispositivos legais que particularizam a experiência de ensinar História em níveis estadual e municipal. Iniciativas dessa natureza podem demonstrar quão simplista e estereotipado é afirmar que o ensino de História foi "tradicional".

Uma proto-iniciativa foi empreendida por Primitivo Moacyr, ex-funcionário da Câmara Federal, que compilou a legislação educacional dos séculos XIX e de parte do XX. Como era comum aos membros da elite letrada do novecentos, Moacyr foi professor de primeiras letras, por concurso, no interior 
da Bahia, sua terra natal. No final da década de 1880, a convite do presidente da província de Pernambuco, tornou-se inspetor do Liceu de Recife. De lá, partiu para a cidade do Rio de Janeiro para cursar Direito. Já no regime republicano, tornou-se redator dos debates parlamentares na Câmara Federal, posto que ocupou até se aposentar em 1933. Durante a temporada como redator da Câmara, publicou um livro (em 1916) e diversos artigos em jornais, sempre sobre instrução pública e, após a contribuição no serviço público, publicou 15 volumes que versam sobre a instrução no Império, na República e no Estado de São Paulo (OLIVEIRA, 2014; CARVALHO; MACHADO, 2018).

O trabalho de Moacyr vale como fonte secundária e, também, como estímulo ao trabalho de comparação. A leitura da legislação compilada por Primitivo Moacyr, em especial a relativa às províncias, é reveladora de uma série de aspectos da História do ensino de História no Brasil do século XIX. Contribui para o esforço de avançar para além das ideias padronizadoras acerca dessa prática pedagógica. Quando conhecemos minimamente aquilo que se expressava em diferentes províncias, percebemos a variedade de situações que questionam a tese de que o Colégio Pedro II determinava o que deveria ser ensinado em História em escala nacional.

Um primeiro aspecto a se destacar é o próprio título ou rubrica da disciplina escolar. Este é considerado um marcador fundamental dos principais estudos sobre História do ensino de História para estabelecer sua cronologia e periodização, ou seja, um nome que a diferencie de outras áreas de estudos escolares. A legislação compilada revela, porém, que havia uma miríade de nomenclaturas. O componente curricular aparece sob a alcunha genérica "história", às vezes associada à expressão "em especial do Brasil" ou "história universal", "história geral" e "do Brasil” ou às famosas subdivisões: antiga, medieval, moderna e contemporânea. Isto para não falar de nomenclaturas incomuns ao ensino contemporâneo, como História Geral Profana e História Sagrada, presentes na proposta de criação de um Colégio de Belas-Artes na província do Pará em 1827. Ou, ainda, História Militar, presente na proposta apresentada por D. João VI para a criação de um curso de Ciências Exatas e de Observação em 1820 .

Poder-se-ia argumentar que tal variação pode indicar uma cronologia temporal clara e distinta, mas não é isso que percebemos ao examinar os casos particulares. Os mais diferentes nomes aparecem em tempos e lugares distin- 
tos, inclusive nas diversas reformas implementadas pelos governos provinciais. Cada novo reformador aposentava ou restituía diferentes nomenclaturas. Veja-se o caso do ensino de História Sagrada: a título de exemplo, podemos encontrar referências a ela na reforma implementada em 1867 no programa do Colégio do Espírito Santo, na província de mesmo nome; foi subtraída em reforma posterior e retornou em 1877. E é a mesma disciplina escolar que pode ser encontrada na legislação de Minas Gerais no ano de 1852 e no Rio de Janeiro, na mesma década. Não há, portanto, uma rubrica. Há várias designações. Por isso, a nomenclatura não parece ser um delimitador muito preciso para compreender o percurso histórico desta disciplina em termos de Brasil.

Outra característica apontada nos estudos balizadores em História do ensino de História, para definir uma periodização, diz respeito à centralidade do Colégio Pedro II. Segundo esta perspectiva, foi a partir daquela instituição e de seus programas de estudos que se organizariam as instituições congêneres provinciais. Não obstante esta afirmação ser extremamente difundida, a leitura da compilação de Moacyr indica não mais que duas menções ao Colégio e seus programas de estudos. Uma referente à província de Minas Gerais, quando o presidente propõe a criação de um Liceu que adote todas ou quase todas as cadeiras do Colégio Pedro II, e outra relativa à província da Bahia, quando o presidente ordena que o Liceu local adote o programa daquela instituição. Ambas as menções datam de 1848.

Há também outro aspecto que não demonstra padronização a partir de um locus modelar. Referimo-nos, principalmente, à organização própria para o estudo em formato escolar. Não são apenas os nomes que variam, como vimos anteriormente. A orientação sobre a abordagem do assunto também difere de local a local. Na legislação compilada, não faltam exemplos oriundos das províncias que indicam uso de quadros comparativos, associação do estudo da História com a aprendizagem de leitura, adoção dos mais diversos materiais de apoio. A compilação elaborada por Moacyr revela um grande laboratório pedagógico distribuído pelo território brasileiro.

Se Moacyr intuitivamente apontava a necessidade de comparação entre as províncias, porque os historiadores do nosso tempo não praticam a alternativa metodológica? É certo que os lapsos intuitivos do pernambucano, em termos de comparação, estavam impregnadas da ideia de extrair modelos para "aperfeiçoar sistemas com transformações e modificações”, uma tendência que 
vigorou, sobretudo entre os estadunidenses do primeiro terço do século passado (RUST et al., 2012, p. 158-159). Mas nada nos impede (e, agora, muito mais aparelhados) que ponhamos em prática um vigoroso projeto de investigação sobre o pensamento e a prática do ensino de História em cada um dos estados da Federação.

No que diz respeito ao que nos interessa de perto, a experiência republicana, e mesmo na compilação de Moacyr, poderíamos executar a comparação do tipo assimétrico (HAUPT e KOCKA, 2009, pos. 118), legitimando, por exemplo, o cotejo de experiências entre Estados de grande poder político econômico, como São Paulo e Minas Gerais, e estados praticamente inexpressivos em número de deputados e de receita, como Sergipe e Rio Grande do Norte, durante a Primeira República. Em termos heurísticos, a referida compilação já nos permite inventariar problemas indiretamente revelados pela legislação e suas respectivas propostas de soluções.

No que diz respeito ao ensino de História, é revelador observar a baixa matrícula de alunos nas aulas de História (nas suas mais variadas denominações) em todas as províncias. As medidas reformistas adotadas indicam não apenas diferentes projetos de constituição de pessoas, mas também um esforço no sentido de ampliar efetivamente o público para o qual estes projetos eram pensados. Cabem, por exemplo, pesquisas que se voltem para o questionamento de um componente curricular História que tinha como finalidade a formação da nacionalidade brasileira, o que veio a ser irrefletidamente compreendido como "ensino tradicional".

As pesquisas comparativas também podem problematizar essa máxima da Historiografia e verificar alcance efetivo da malha escolar em diferentes períodos. Esse tipo de investigação poderia, quem sabe, ir de encontro ao discurso do senso comum, equivalente à tese do professor doutrinador dos tempos atuais. Como formar uma nação, a partir do ensinar História, quando tão poucos tiveram acesso a essa informação?

\section{A COMPARAÇÃO TRANSNACIONAL}

Uma das tibiezas demonstradas pela pesquisa histórica sobre o ensino de História no Brasil está, exatamente, nas iniciativas de abordar tal objeto para além das fronteiras da nação. Parece-nos, em parte, a obediência a uma inter- 
pretação equívoca do princípio historicista de que os estudos da nossa área não se acomodariam bem em tarefas que contrastassem experiências assimétricas, como a comparação do ensino de História dos Estados Unidos da América (EUA) e do Brasil ou até a comparação entre os pensamentos e práticas do ensino e da aprendizagem histórica entre os países da América Latina. Os diferentes não seriam comparáveis.

Recentemente, e de maneira tímida, algumas iniciativas têm sido empreendidas entre dois países, a exemplo de Brasil e Argentina. Empreendimentos mais ambiciosos esbarram, contudo, no nosso pouco afeto (ou no nosso preconceito) com os povos de língua espanhola situados nas regiões andinas. É como se a América Latina estivesse ao fundo e a Europa fosse o nosso nascer do sol.

Claro que não é invenção dos colegas que pesquisaram nos anos 80 do século passado. Há certa inclinação, mesmo nos primeiros anos da nossa República (e foi assim também na Argentina e no Chile, por exemplo) pela busca de exemplos do ensino de História na França e na Alemanha. O nosso João Ribeiro que o diga. Até hoje, o festejado livro didático de 1900, História do Brasil, tem sua fama atrelada à apropriação de modelos ingleses e alemães de ensinar História.

Importante é afirmar que tal situação pode ser revertida e sem grandes esforços financeiros ou de pessoal. As relações tecidas entre Brasil e demais repúblicas americanas, ao longo do século XX, têm gerado uma série de documentos que testemunham os movimentos da nossa política externa, sobretudo com a França, os Estados Unidos, a Inglaterra e a Alemanha.

Dentre esses documentos estão as convenções das quais o Brasil foi signatário ou protagonista da sua construção. É certo que a maioria das seis Conferências Pan-Americanas - ocorridas em Washington (1889/90), Cidade do México (1901/2), Rio de Janeiro (1906), Buenos Aires (1910), Santiago de Chile (1923), Havana (1928), Montevidéu (1922), Lima (1938), Bogotá (1948) e Caracas (1954) - mobilizaram os países em tornos de conflitos comerciais, militares e financeiros. Mas também experimentamos acordos educacionais, sobretudo quando esses entes receberam os influxos das duas guerras mundiais.

Em nível continental, as disputas por dominação envolveram, principalmente, as repúblicas de língua espanhola e os EUA, com o Brasil, na maioria dos casos, alinhado à potência do Norte. Em que medida esses jogos de força 
teriam impactado a produção de políticas públicas educacionais, nomeadamente, para o ensino de História?

Um exemplo de pesquisa frutífera a respeito, fornece-nos Juçara Luzia Leite. Ela informa sobre a efetivação do "Convênio entre o Brasil e a República Argentina para a Revisão dos Textos de Ensino de História e Geografia” (LEITE, 2010, p. 103-104). A iniciativa nascia na esteira de empreendimentos do mesmo gênero, ocorridos entre alguns países europeus (França, Alemanha e Espanha), logo após o fim da Primeira Guerra Mundial. Naquela época, acreditava-se que uma das causas da guerra estava no cultivo da xenofobia, transmitida pelos livros didáticos de História. Em que medida as propostas de revisão europeias impactavam a proposta sul-americana? Que relação podemos estabelecer entre os critérios de revisão estabelecidos por esse acordo, em 1933, e os critérios de avaliação da qualidade dos livros didáticos de História estabelecidos pela Comissão Nacional do Livro Didático, no Brasil de 1938 ? Haveria uma disputa teórica entre quadros teóricos orientadores do livro didático de História capitaneados por autores como E. Claparéde e J. Piaget, na Europa, e J. Dewey, nos EUA? As questões permanecem em aberto.

Outra possibilidade de investigação transnacional, ${ }^{1}$ envolvendo idênticos protagonistas, nos é oferecida pela documentação relativa à $7^{\text {a }}$ Conferência Internacional Americana, ocorrida em 1933, na cidade de Montevidéu, ${ }^{2}$ onde delegados de Argentina, Brasil e Uruguai propuseram e lideraram os trabalhos de discussão e aprovação da "Convenção sobre o Ensino da História", trazendo para o âmbito da Conferência a preocupação com a narrativa histórica presente nos manuais escolares e no ensino dos "jovens" americanos. ${ }^{3}$

A Convenção foi organizada em 8 artigos, com o objetivo geral de "complementar a organização política e jurídica da paz com o desarmamento moral dos povos, revendo os textos didáticos utilizados nos diversos países”. ${ }^{4}$ Logo nos primeiros artigos fica evidente a percepção da narrativa histórica escolar como potencial instrumento de fomento para a "amizade" ou "rivalidade" entre os povos americanos. ${ }^{5}$

Os artigos indicavam a necessidade de superação do desconhecimento mútuo, e a promoção da circulação de informações entre os estudantes americanos, inclinando-os a assumirem visões amistosas sobre seus vizinhos através do conhecimento histórico. Em geral, contudo, a "história patriótica" ensinada nas escolas americanas do começo do século XX contribuía para a 
construção de identidades nacionais baseadas na superação de um Outro potencialmente desagregador. À pretensão de fomentar uma instituição continental que orientasse os sistemas educacionais dos países americanos somou-se, então, a necessidade de superação das rivalidades entre os estados presentes nas narrativas dos manuais escolares, como está explícito do Artigo $3^{\circ}$ da referida Convenção.

Criar um "Instituto para o ensino da História das Repúblicas Americanas", com sede em Buenos Aires, encarregado de coordenar a realização interamericana dos propósitos enunciados e cujos fins serão recomendar-se que se:

a) Fomente em cada uma das Repúblicas Americanas o ensino da História das demais;

b) Dedique maior atenção a história da Espanha, Portugal, da Grã-Bretanha e da França e de quaisquer outros países não americanos, naqueles pontos de maior relação com a história da América;

c) Procures que os programas de ensino e os Textos de História não contenham apreciações hostis para outros Países ou erros que tenham sido evidenciados pela crítica;

d) Atenue o espírito bélico nos manuais de história no estudo da cultura dos povos e o desenvolvimento universal da civilização para determinar a parte que coube na civilização de cada país aos estrangeiros;

e) Elimine aos textos os paralelos fastidiosos entre as personagens históricas nacionais e estrangeiras e os comentários e conceitos ofensivos e deprimentes para outros países;

f) Evite que a narração das vitórias alcançadas sobre outras nações possam servir de motivo para rebaixar o conceito moral dos países vencidos;

g) Não julguem com ódio ou se adulterem os feitos na narração de guerras ou batalhas cujo resultado haja sido adverso e

h) Destaque tudo quanto possa contribuir construtivamente à inteligência e cooperação dos países americanos.

No desempenho das Altas funções educativas que se lhe cometem, o Instituto para o Ensino da História conservará estreitos vínculos com o Instituto PanAmericano de Geografia e História, que funciona na cidade do México, estabelecido como órgão de cooperação entre os Institutos Geográficos e Históricos das Américas e com as demais entidades de fins similares aos seus. (CONVENCION, 1933, p. 4) 
As recomendações acima elencadas revelam aspectos importantes acerca da percepção que se tinha entre os delegados da Conferência sobre as mudanças necessárias no ensino da História. Torna-se evidente a preocupação em mitigar narrativas históricas calcadas na rivalidade entre os Estados, outrora instrumentos privilegiados para construção das identidades nacionais e seus respectivos heróis.

Nesse sentido, a presença de termos como "amizade", "ódio", “ofensas" e "rivalidades", conferindo aos Estados independentes sentimentos atribuídos às relações humanas, enseja interessante debate sobre o processo de imaginação das identidades nacionais como entidades uniformes, assim como a seleção do que deveria ser valorizado ou não como expressão dessas identidades no ensino de História (ANDERSON, 1983).

A Convenção também interferia na História da Europa que se deveria ensinar. "Maior atenção" dever-se-ia dar às histórias de Portugal, Espanha, Grã-Bretanha e França, credenciando os países americanos a integrarem a ideia de progresso universal da civilização forjado na Europa, ratificado posteriormente na explícita determinação da publicação da Convenção nos idiomas espanhol, português, francês e inglês. Não deixa de ser intrigante, entretanto, o fato de que os representantes do Paraguai e da Bolívia subscreveram a Convenção sobre o Ensino de História, mesmo estando naquele momento envolvidos no conflito militar conhecido como a Guerra do Chaco (1932-1935).

Cabe destacar que os representantes do governo dos Estados Unidos, ainda que tenham elogiado a iniciativa, alegaram impedimento constitucional para subscrever o documento, uma vez que seu sistema de ensino seria de responsabilidade dos estados e municípios. Esse fato indica singularidades e distanciamentos entre os sistemas de ensino e, de certa forma, abre a possibilidade de exame de um protagonismo de países latino-americanos no contexto da promoção da "amizade hemisférica" através do ensino.

\section{AMPLIANDO O CONHECIMENTO E CONCLUINDO}

Ao sugerir o repensar sobre objetos e abordagens, tornando a História do ensino de História mais pluralista e menos estereotipada, não propomos fazer tábula rasa da produção historiográfica dos anos 80 e 90. De onde retiraremos o material para uma nova escrita de síntese sobre a História do ensino de História? 
Evidentemente, nós as colheremos junto aos pesquisadores da área. Eles se agrupam em associações como a Associação Nacional de História (ANPUH-BR) e a Associação Brasileira de Ensino de História (ABEH), que se renovam em eventos bianuais como o Simpósio Nacional de História, o Encontro Nacional dos Pesquisadores do Ensino de História e o Encontro Nacional Perspectivas do Ensino de História. A maioria deles está radicada aos institutos públicos de pesquisa, Universidades, cursos de pós-graduação em História e em Educação.

É nesse ambiente que floresce a historiografia sobre o ensino de História. Ela foi episódica, ao longo dos três terços do século XX, e hoje já conta com milhares de trabalhos distribuídos entre teses, dissertações, artigos em periódicos especializados e comunicações. Com a instituição do Programa Interinstitucional de Bolsas de Iniciação à Docência (PIBID) e do Mestrado Profissional em Ensino de História (ProfHistória), essa quantidade de trabalhos pode até duplicar nos próximos quatro anos.

Contudo, tal bibliografia deve ser revisitada à luz de demandas da prática do ensino de História hoje e até mesmo das demandas por representação na Federação brasileira. Nesse sentido, ela é lacunar porque conhecemos pouco sobre o século XIX e muito menos sobre as centúrias precedentes. É lacunar porque explora bastante os conteúdos dos livros didáticos, e não dos seus usos, as identidades do professor, e não dos elementos que constituem a sua formação inicial, as dificuldades de aprendizagem, e não o perfil do aluno que emerge, por exemplo, da experiência digital do final do século XX. É lacunar também porque pouco trata de finalidades e nada explora sobre progressão das aprendizagens históricas. Além disso, a historiografia sobre o ensino de História permanece bastante endógena, levando à hipercrítica sobre a experiência brasileira, quando países exportadores de modelos como a Alemanha e a França, no século XIX, e os EUA e a Argentina, no século XX, vivenciaram problemas semelhantes aos nossos.

A ausência de uma historiografia comparada afeta até mesmo a distorção da experiência nacional. Como as casas editoriais, os colégios modelos e as instituições formadoras pioneiras no ensino superior de História estão localizadas no centro-sul do país, as singularidades das demais regiões ficam obscurecidas. A historiografia sobre o ensino de História, por outro lado, fornece material que revela diversidade e singularidades locais, permitindo a apresentação de diferentes respostas para problemas urgentes em termos de finalida- 
des, conteúdos, avaliação, aprendizagem, progressão, materiais didáticos e usos sociais da história. As diferentes possibilidades de resposta, entretanto, junto às lacunas e desequilíbrios da pesquisa, apontadas acima, não dificultam trabalhos de síntese, que são fundamentais para a orientação de políticas públicas e para a constante avaliação da prática docente.

As sínteses históricas, enfim, podem ser bastante eficazes se combatermos os equívocos que as levaram a não problematizar a diversidade brasileira. Esta grande narrativa, mobilizada pela luta contra as licenciaturas curtas, a ditadura militar e a desqualificação dos profissionais de História, transmutou-se de uma plataforma política em uma verdade epistêmica e isso não foi bom para a reflexão sobre a formação de professores e o ensino-aprendizagem de História. Cabe-nos transformá-la.

\section{REFERÊNCIAS}

ANDERSON, B. Imagined communities: reflections on the origin and spread of nationalism. New York: Verso, 1983.

BURKE, Peter. A Escola dos Annales, 1929-1989: a revolução francesa da historiografia. $2^{\text {a }}$.ed. São Paulo: Ed. UNESP, 2010.

CARVALHO, Rosana Areal; MACHADO, Raphael Ribeiro. A História da Educação Brasileira na produção de Primitivo Moacyr. Revista de História e Historiografia da Educação, Curitiba, v. 2, n. 4, jan./abril 2018, p. 147-169.

CONVENCION sobre la enseñanza de la Historia. Montevideo, 1933. Disponível em: https://catedrareyes.files.wordpress.com/2017/04/oea-convecic3b3n-historia-1933. pdf. Acesso em: 18 de nov. 2018.

DOSSE, François. A história em migalhas: dos Annales à Nova História. São Paulo: Ensaio; Campinas: Ed. Unicamp, 1994.

FONSECA, Thaís Nívia de Lima e. História \& ensino de história. 2. ed., História \& reflexões. Belo Horizonte: Autêntica, 2004. 120 p.

FREITAS, Itamar. Histórias do ensino de História no Brasil. Vol. 1. São Cristóvão: Editora da UFS, 2006.

FREITAS, Itamar. Histórias do ensino de História no Brasil. Vol. 2. São Cristóvão: Editora da UFS, 2010.

FREITAS, Itamar; SEMEAO, J. D.; OLIVEIRA, Margarida Maria Dias de. O Contempo- 
râneo e o Tempo Presente nos Currículos Escolares de História nos EUA e no Brasil (2002-2012). Cadernos do Tempo Presente, v. 11, p. 1, 2013.

FREITAS, Itamar; OLIVEIRA, Margarida Maria Dias de. A formação do profissional de história na contemporaneidade. Mouseion, [Porto Alegre], v. 19, p. 109-125, 2014.

FREITAS, Itamar; OLIVEIRA, Margarida Maria Dias de. Historiografia didática e prescrições estatais sobre conteúdos históricos em nível nacional (1931-2012). Territórios e Fronteiras, Cuiabá, v. 6, p. 6-18, 2013.

FREITAS, Itamar; OLIVEIRA, Margarida Maria Dias de. "Papai, para que serve a história?”: funções e sentidos da aprendizagem histórica na literatura recente colhida na Espanha e apropriada pelos brasileiros. Tempos Gerais, São João del Rei, v. 4, p. 1-13, 2015.

HAUPT, Heinz-Gerhard; KOCKA, Jürgen. Comparison and beyond: traditions, scope and perspectives of comparative History. Comparative and transnational approaches and new perspectives. New York: Berghahn Books, 2012.

JANOTTI, M. L. M.. Historia, Politica e Ensino. In: Circe Bittencourt (Org.). O saber histórico na sala de aula. São Paulo: CONTEXTO, 1997, p. 42-53.

LEITE, Juçara Luzia. Professores e políticos em nome da paz: interesses internacionais por uma história ensinada. Saeculum (UFPB), v. 22, p. 103-113, 2010.

MOACYR, Primitivo. A Instrução e as Províncias: subsídios para a História da Educação no Brasil. São Paulo: Cia Editora Nacional, 1940. (03 vol.)

MOACYR, Primitivo. A Instrução e o Império. São Paulo: Companhia Editora Nacional, 1936. (03 vol.)

NADAI, Elza. O ensino de História e a "pedagogia do cidadão". In: PINSKY, Jaime. O ensino de História e a criação do fato. 14. ed. São Paulo: Contexto, 2011 [1988], p. 27-35.

NEVES, Joana. Como se estuda História. In: Revista de Ciências Humanas. João Pessoa, UFPB/CCHLA, 1980, trimestral, Ano $2 \mathrm{n}^{\circ} 4$.

OLIVEIRA, Luiz Antônio de. Tessituras do Ensino Público: a unidade em Primitivo Moacyr (1910 - 1930). 202f. Tese (Doutorado em Educação) - Universidade Estadual de Maringá, 2014.

OLIVEIRA, Margarida Maria Dias de; FREITAS, Itamar. Currículos de História e expectativas de aprendizagem para os anos finais do ensino fundamental no Brasil (20072012). Revista História Hoje, v. 1, p. 1, 2012.

OLIVEIRA, Margarida Maria Dias de. O direito ao passado: uma discussão necessária à formação do profissional de História. São Cristóvão: Editora da UFS, 2012.

REVEL, Jacques (Org.). Jogos de Escala: a experiência da microanálise. Rio de Janeiro: Ed. FGV, 1998. 
RICOUER, Paul. A memória, a história e o esquecimento. Campinas: Ed. Unicamp, 2007. RÜSEN, Jörn. Teoria da história: Uma teoria da história como ciência. (Trad. Estevão de Rezende Martins). Curitiba: Ed. UFPR, 2015.

RUST. Val D.; JOHNSTONE, Brian; ALLAF, Carine. Reflexões sobre o desenvolvimento da educação comparada. In: COWEN, Robert; KAZAMIAS, Andreas M.; ULTERHALTER, Elaine. Educação comparada: panorama internacional e perspectivas. Brasília: Unesco, 2012, p. 153-172.

WEINSTEIN, Barbara. Pensando a história fora da nação: a historiografia da América Latina e o viés transnacional. In: Revista Eletrônica da ANPHLAC, n. 14, 2013.

WINEBURG, Sam. Historical Thinking and other unnatural acts: charting the future of teaching the past. Temple University Press: Philadelphia, 2001.

\section{NOTAS}

${ }^{1}$ Transnacional com o significado de processos ou resultado de processos que escapam ao aparato de controle do estado-nação e que, ao mesmo tempo, valorizam a categoria estado-nação como instrumento para a compreensão da modernidade (WEINSTEIN, 2013).

${ }^{2} \mathrm{~A} 7^{\mathrm{a}}$ Conferência também se destaca pelo fato de ter sido a primeira da série a aceitar mulheres nas delegações dos países. Ver: MARQUES, Teresa Cristina de Novaes. Entre o Igualitarismo e a Reforma dos Direitos das Mulheres: Bertha Luz na Conferência Interamericana de Montevidéu, 1933. In: Estudos Feministas, Florianópolis, 21(3): 496, set.-dez. 2013.

${ }^{3}$ Deve-se pontuar inciativas semelhantes anteriores ocorridas em outros fóruns, como o Congresso de História Nacional de Montevideo (1928); Congresso de História de Buenos Aires (1929); Congresso de História de Bogotá (1930); Segundo Congresso de História Nacional do Rio de Janeiro (1931), sugerindo uma preocupação cada vez maior com o ensino de História articulado a política interamericana.

${ }^{4}$ No original: "Complementar la organizacíon política y jurídica de la paz con el desarme moral de los pueblos, mediante la revision de los textos de enseñanza que se utilizan en los diversos países."

${ }^{5}$ Artigo $1^{\circ}$. Efetuar a revisão dos textos adotados para o ensino em seus respectivos países, a fim de depurá-los de tudo quanto possa excitar, no ânimo desprevenido da juventude, a aversão a qualquer povo americano.

Artigo $2^{\circ}$. Revisar periodicamente os testos adotados para o ensino das diversas matérias, a fim de submetê-lo as mais recentes informações estatísticas gerais, com o objeto de oferecer neles uma noção mais aproximada e exata da riqueza e da capacidade de produção das Repúblicas Americanas. (CONVENCION, 1933)

Artigo recebido em 11 de junho de 2020. Aprovado em 15 de julho de 2020. 